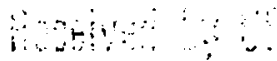

NOV 161989

\title{
FINDING THE MAGNETIC CENTER OF A QUADRUPOLE TO HIGH RESOLUTION - A DRAFT PROPOSAL -
}

\author{
G.E.Fischer, J.K.Cobb, D.R.Jensen \\ Stanford Linear Acceleratov Center \\ Stanford University, Stanford, California 94909
}

\section{Introduction}

In a companion proposal ${ }^{[2]}$ it is proposed to align quadrupoles of a transport line to within transverse tolerances of 5 to 10 micrometers. Such a proposal is meaningful only if the effective magnetic center of such lenses can in fact be repeatably located with respect to some external mechanical tooling to comparable accuracy. It is the purpose of this note to describe some new methods and procedures that will accomplish this aim. It will be shown that these methods are capable of yielding greater sensitivity than the more traditional methods used in the past. ${ }^{\left[\left[^{3]}\right]\right.}$ The notion of the "nodal" point is explcited.

\section{Concept}

Consider the arrangement depicted in Figure 1. A fine wire is suspended through a quadrupolar field, fixed at each end at coordinates $x_{1}, y_{1}, z_{1}$ and $x_{2}, y_{2}, z_{2}$. The tension in the wire is effected by the hanging weight $W=m g$. An infinitesimal disturbance $\delta x$ is introduced at coordinate 1 . The wire will eyecute resonant oscillations at modal frequencies n given by:

$$
f_{\mathrm{n}}=\frac{n}{2 D} \sqrt{T / \mu}
$$

in which $\mathrm{D}$ is the length of the suspension and $\mu$ is the mass per unit length.

\footnotetext{
"Work supported by the Department of Energy, contracts DE-AC03-76SF00515
} 
If the two end:s of the wire are connected to form a loop (the return wire bring stationary with respect to the magnetic field) a voltage will be developed across the terminals that is characteristic only of the induction that the wire is cutting. For the purposes of a simple calculation, let $x_{1}=x_{2}=x$ and $y_{1}=y_{2} \approx 0$. For $D \gg L$ we can write:

$$
x=x_{0}+a \sin (2 \pi f t)
$$

in which $x_{0}$ is a constant offset from the axis and $a$ is the amplitude of ascillation. The voltage then developed will be:

$$
E=-d \Phi / d t=-d B A / d t=-d(k x)(L x) / d t
$$

in which $k$ is the gradient of the magnet such that $B=k x$ and $L$ is its effective magnetic length. Substituting for $x$ and differentiating we obtain two terms for the voltage:

$$
E=2 k L a \omega\left[x_{0} \cos \omega t+a \sin 2 \omega t\right]
$$

the first at the first harmonic of the driving frequency proportional to the offset, the second a term inclependent of the offset at the second harmonic. As expected, this equation demonsirates the benefit on signal strength of being able to use relatively high oscillating frequencies.

\section{Some experimentally relevant numerical parameters}

\subsection{THE WIRE}

For a simple test we have chosen the length of the wire to be $100 \mathrm{~cm}$. Using a $1.5 \mathrm{mil}(38 \mu)$ gold plated tungsten wire, density say $19 \mathrm{gr} / \mathrm{cc}$, the calculated frequency of the fundamental, with a mass $m_{i}=25 \mathrm{gr}$ providing the tension is 47 $\mathrm{Hz}$. The observed frequency was $49 \mathrm{~Hz}$. 


\subsection{Signal Stkength}

The magnet was $20 \mathrm{~cm}$ long, had a bore diameter of $1 \mathrm{~cm}$ and a pole tip field of 1.2 Tesla. Hence the integrated gradient strength $\mathrm{kL}$ was $48 \mathrm{Tesla}$. It is not possible to measure the amplitude $\mathrm{a}_{\mathrm{a}}$ " but we can judge the sensitivity to offset as follows. If the second harmonic term is equal to the first in peak voltage then $a=x_{0}$. Let "a" be 30 microns, then we may expect to see rms voltages of about 19 microvolts. Put slightly differently the sensitivity would be $0.63 \mu \mathrm{V} /$ micron.

\section{Some experimental results}

A photograph of the apparatus is shown in Figure 2. The pulley transferring the weight $W$ into tension is in fact a balanced razor blade. It was necessary to take great care that the mechanical shaker did not introduce unwanted mechanical motions or generate a common mode field that could be picked up by the flux loop. It was found that a 4 inch loud speaker pushing on a fiber rod, pushing on the wire mount, (or better yet on the wire directly) produced stable, non-interfering oscillations of the wire.

The very first plot of signal versus off-set (one end only) is shown in Figure 3. The resolution of detecting the null point and repeatability of the micrometer settings was $\dot{0} .0001$ inches or about 2.5 microns. Linear fits to the data are indicated.

Improved wire shaking techniques led to the data taken one week later which is shown in Figure 4a. and Table 1. The ability to find the intercept can be inferred from Figure 4b. It is about 1 micron. This translates to 0.5 micron at the quadrupole.

In order to achieve a good null it was useful to adjust the orthogonal coordinate by iterating. The sensitivity to the coordinate at right angles to the motion is not severe. This is apparent when one examines the flux lines of a quadrupole. The flux lines are parallel to the motion are not cut. 
The signal was also processed by a lock-in amplifier ${ }^{|0|}$ with which the phase of the signal could be unambiguously seen with respect to the driving signal. This detector has several more decades of gain. Attempts to suppress common mode noise continue. We believe the method holds promise of even higher resolution. Best results are obtained after $4 \mathrm{pm}$ and the building environment to mechanical disturbances improves. Footsteps and loud speech currently limit improvements!

\section{The "Nodal" point concept.}

In the foregoing simple sample calculation we have set $x_{1}=x_{2}$. In the experimental world we have no a-priori knowledge that the wire is parallel to the real magnetic axis (whatever this means). What the wire coordinates measure is a family of lines all of whom satisfy the condition that the net flux cut is zero. This is precisely the condition we wish to achieve for the trajectories of the beam particles. To first order then, we have accomplished the task. Setting $x_{1}=\tau_{2}$ is not critical therefore and can be accomplished by more traditional means (jig-transit) if one chooses.

The afore mentioned family of lines should all intersect at a common point. We call this position $z_{o}$ the "nodal" point for it around this point we can rotate the magnet (in yaw and pitch) without deflecting the beam. In practice this point may not lie in the exact axial center of the steel because, as we have observed in earlier studies, coil configurations on the lead and non-lead ends of the magnet are not identical.

To verify this belief, studies were carried out in the following way: coordinates for a null condition were found, then the wire at one end of the magnet was moved a given distance ( say 60 microns) and the motion required at the other end to restore the null condition recorded. The results were, as expecied, that the motion at other end was equal and opposite within the resolution of the set up. 


\section{Field Use of Centering Data}

It is not sufficient to find the "center" of a lens in the laboratory. One must be able to reproduce the coordinates in the field. Experience with magnets in the past nas shown that they cannot be taken apart and reassembled if one wishes to achieve micron reproducibility. This fact leads to the notion that they must be measured with vacuum chamber in place. This immediately leads to the notion that the same tooling used to position and reference the wire remains permanently attached to the magnet. In fact it becomes the same tooling to which the beam position monitor must be referenced. This notion of carrying part of the calibrating apparatus into the field is not at all unusual in magnetic measurement technique. If one truly wants to reproduce the strength versus current relationship in the field. one often vos the very same current measuring device in the field as that which was used in the lab.

One conceivable (and very simple) readout is shown in Figure 5. Very accurately machined flanges are permanently fixed to the quad bore by clamping the bore tube to the pole pieces. A ring guage with three bearing pads can be rotated in the plane perpendicular to the quad axis. One of the three pads is spring loaded so that the gauge can be mounted on the flange. The micrometer post is run in so that the wire barely touches it. This condition is observed when the oscillating wire shorts to ground periodically. The micrometer reading is recorded. The ring gauge is now rotated by $\mathbf{1 8 0}$ degrees and the process is repeated. The wire must have been half-way between the readings with respect to the edges of the flange. The process is repeated with the wire oscillating in the other plane. The flange, and its mate at the other end of the quadrupole, are the tooling to which the field survey is referenced. 


\section{Proposal}

We intend to develop the method outlined above (we have only scratched the surface of many possibilities that come to mind) and propose that the resulting apparatus and tooling be used in connection with the construction of the Final Focus Test Beam in the coming year.

\section{Acknowledgements}

We gratefully acknowledge Ed Garwin for lending us the lock-in detector and Dan Jones for setting up the driver electronics.

\section{REFERENCES}

1. Final Focus Test Beam Alignment, R.E.Ruland and G.E.Fischer, February 1989

2. Magnetic center location in Multipolar Fjelds, J.K.Cobb and J.J Murray. Nuc.Instr.Methods Vol.45, pl (1967)

3. The most common method used in the past is to identify the magnetic center of a lens with its mechanical center of construction; often "defined" to be centered with respert to its iron pole surfaces, or better, its mechanical split planes.

4. Model HR-8 Princeton Applied Research 


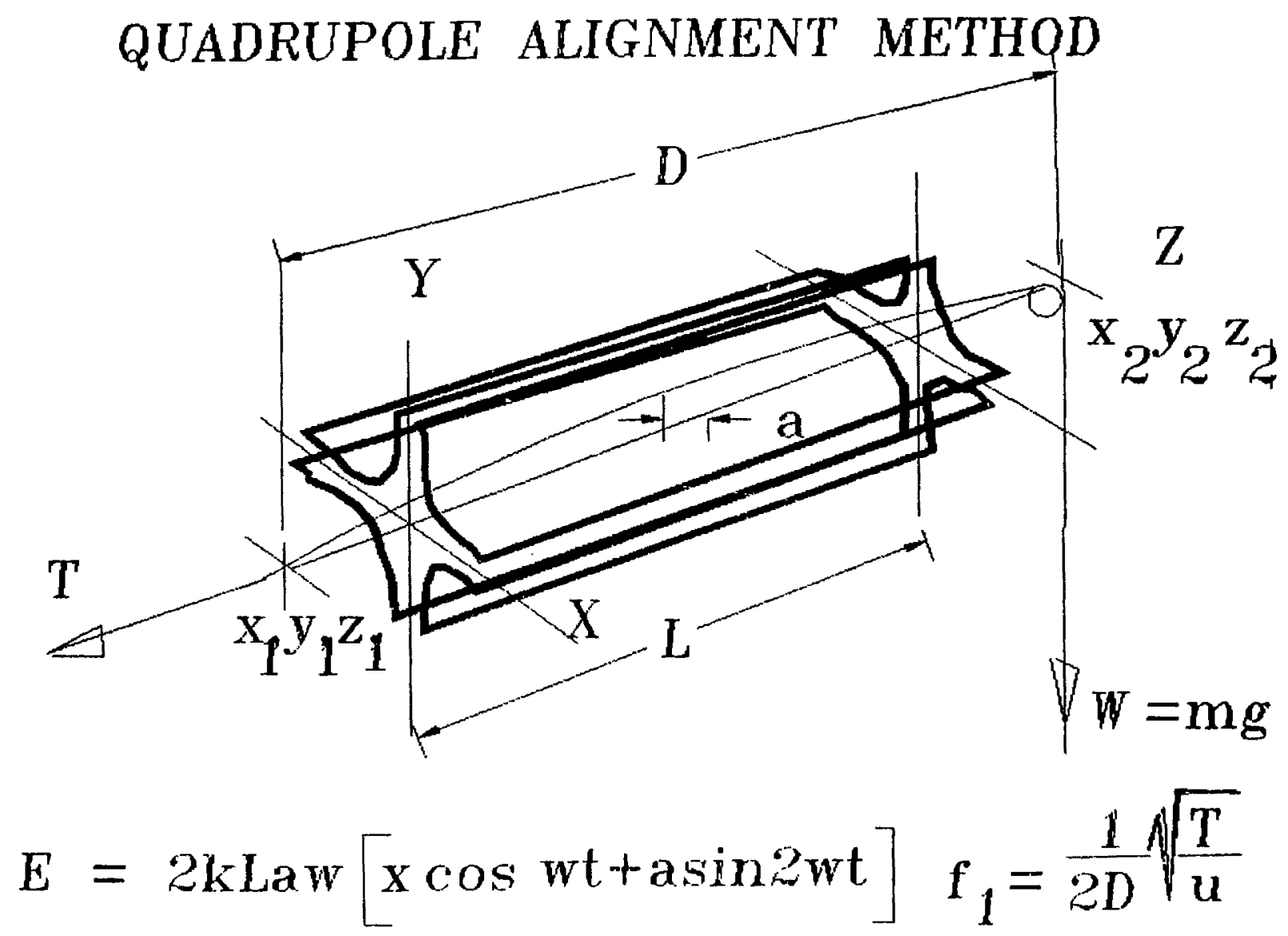




\section{SIGNAL GENERATION AND ANALYSIS}

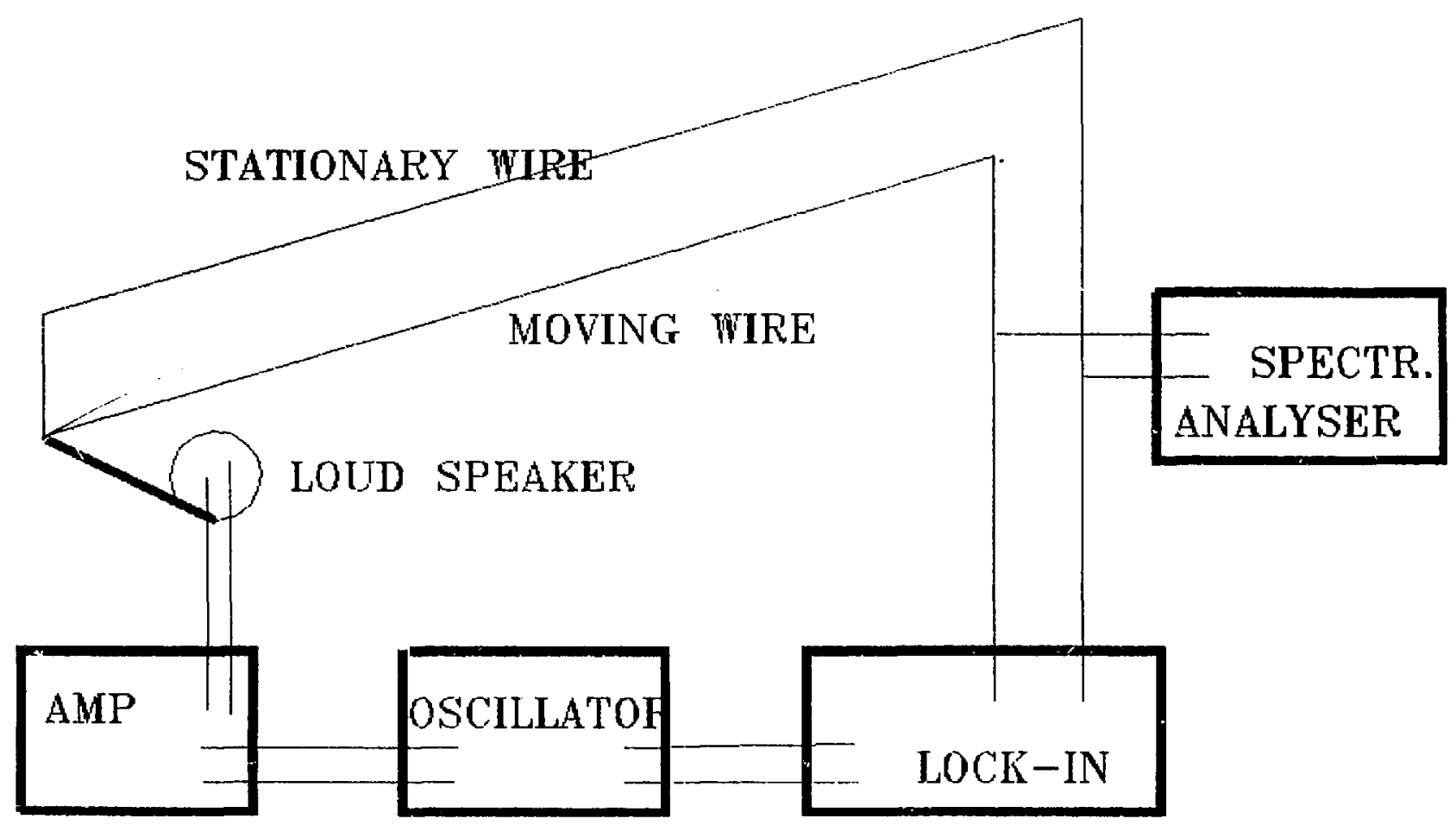




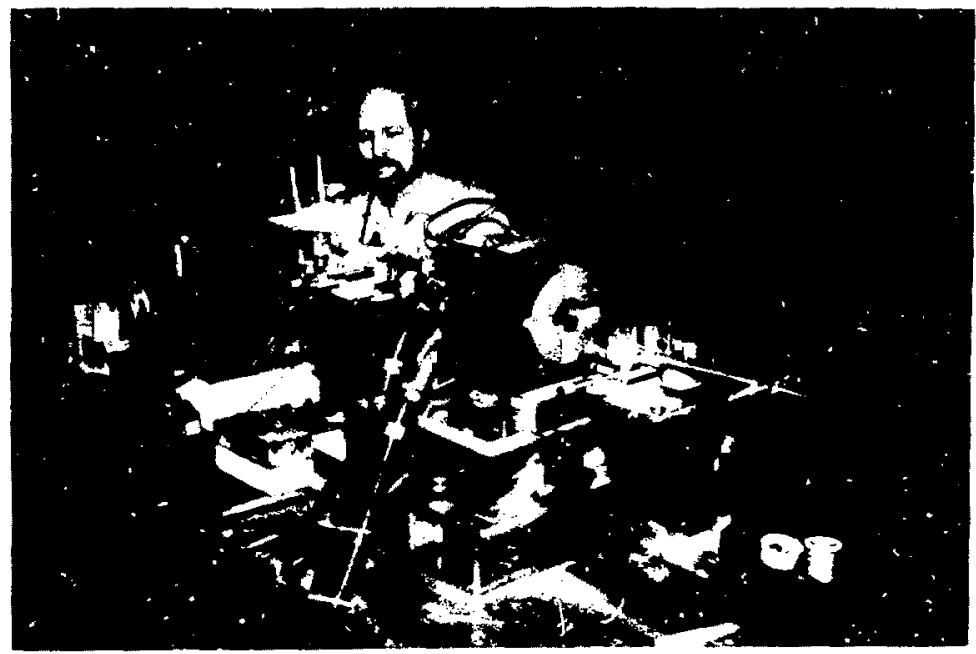

FIF, 2 


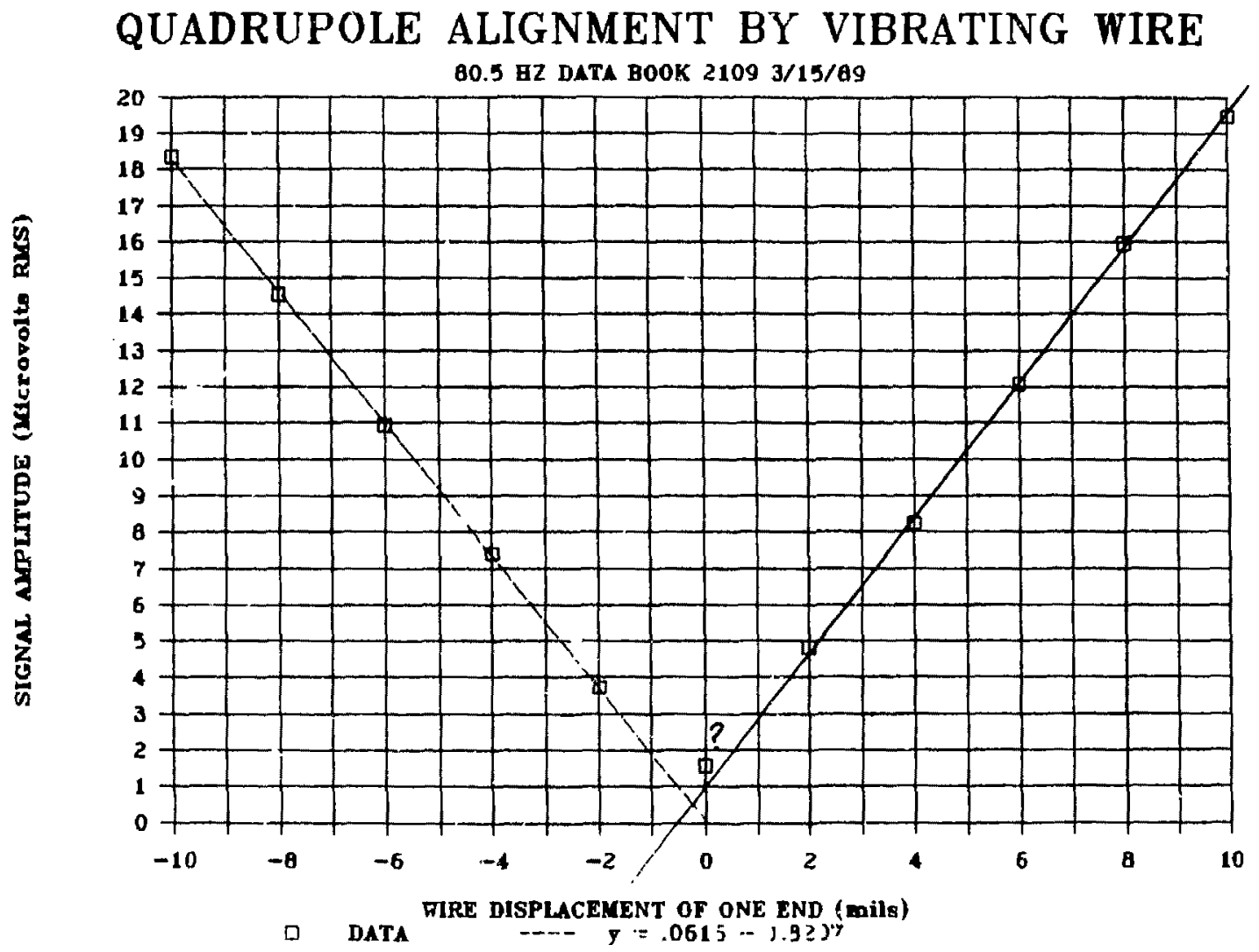

Fig. 3 


\section{QUADRUPOLE ALIGNMENT BY VIBRATING WIRE}

55 HZ DB $21093 / 21 / 89$

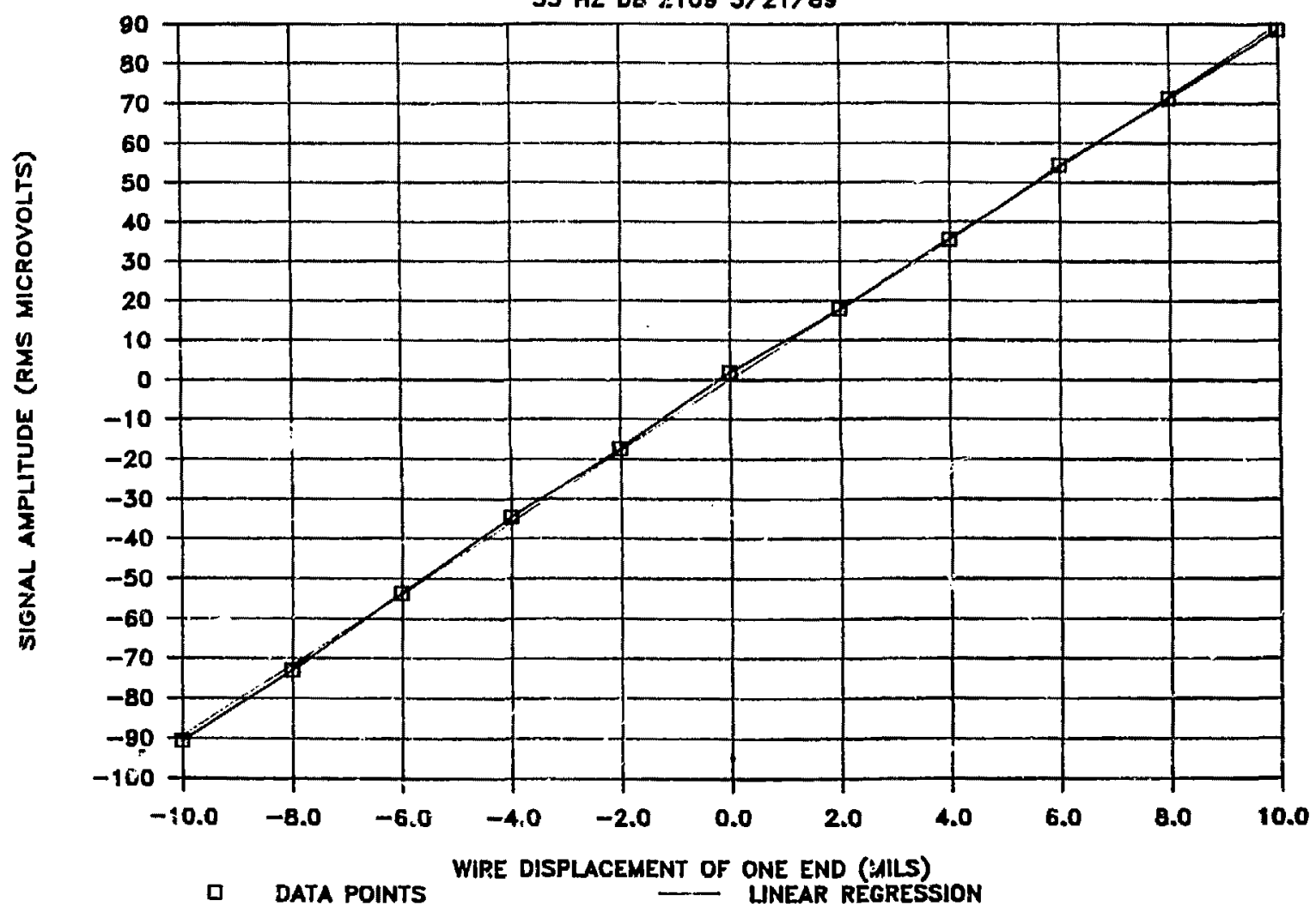

FIG. 4A 
QUADRUPOLE ALIGNMENT BY VIBRATING WIRE

55 HZ DB $21093 / 21 / 89$

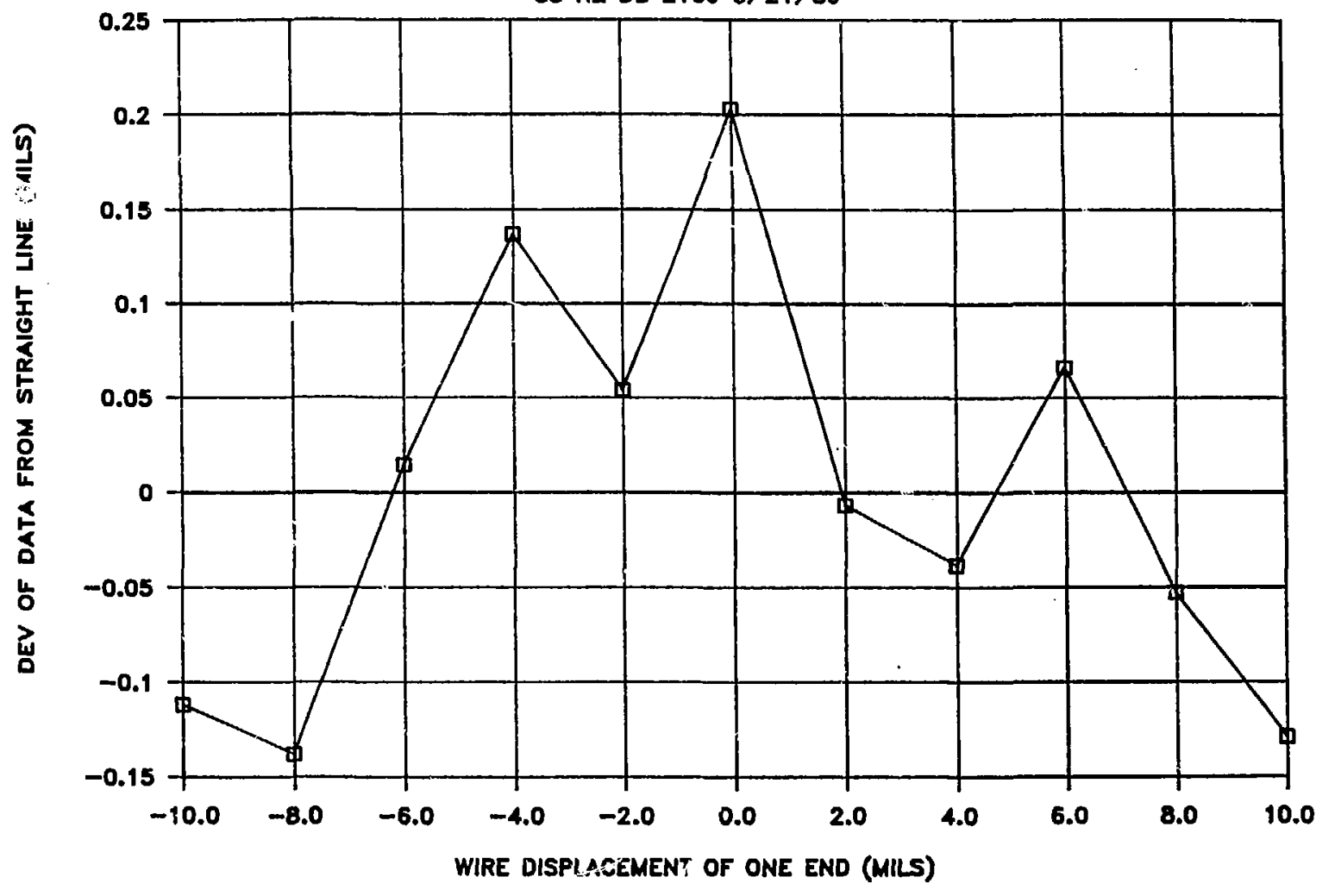

FIG. $4 B$ 


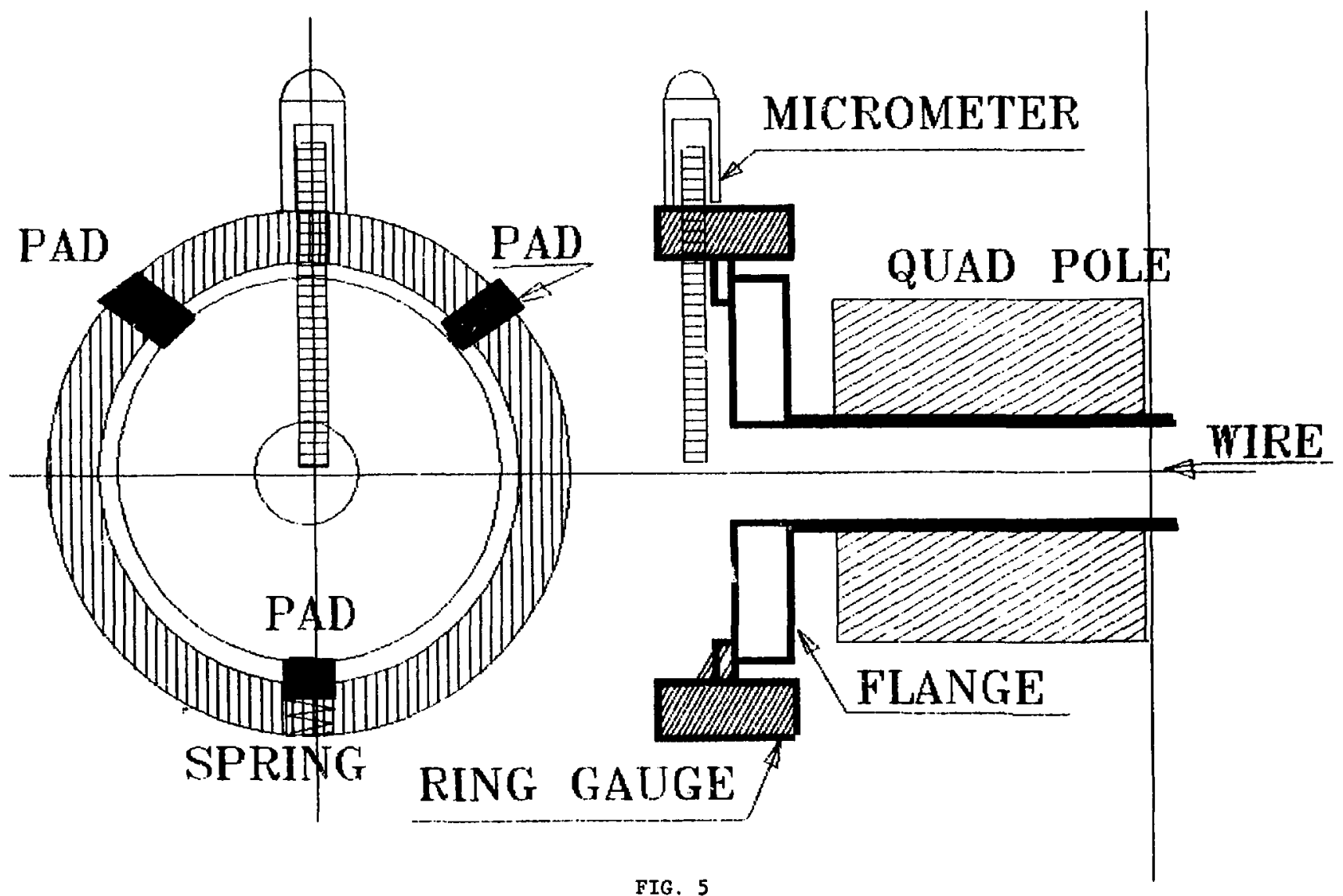


TABLE 1

RUADFUFOLE ALIGNMENT BY VIBRATING WIFE
Data book 2109, page $133,3 / 21 / 89$

\begin{tabular}{|c|c|c|c|c|c|}
\hline WIFE DISF & UVDLTS & UVCLTS & L. Fi. & DELTA UV & DELmiis \\
\hline $\begin{array}{r}-10.0 \\
-0.0 \\
-6.0 \\
-4.0 \\
-8.0 \\
0.0 \\
2.0 \\
4.0 \\
6.0 \\
8.0 \\
10.0\end{array}$ & $\begin{array}{r}90.470 \\
72.780 \\
53.470 \\
34.470 \\
17.290 \\
1.967 \\
18.010 \\
35.650 \\
54.510 \\
72.570 \\
65.610\end{array}$ & $\begin{array}{r}-90.470 \\
-72.780 \\
-55.470 \\
-34.470 \\
-17.890 \\
1.507 \\
1 E .010 \\
55.650 \\
54.510 \\
71.370 \\
88.610\end{array}$ & $\begin{array}{r}-87.468 \\
-71.545 \\
-53.618 \\
-35.675 \\
-17.776 \\
0.147 \\
18.070 \\
35.453 \\
53.915 \\
71.939 \\
89.762\end{array}$ & $\begin{array}{r}-1.002 \\
-1.235 \\
0.131 \\
1.229 \\
0.485 \\
1.820 \\
-0.060 \\
-0.343 \\
0.554 \\
-0.465 \\
-1.152\end{array}$ & $\begin{array}{r}-0.11 E \\
-0.1 \Xi E \\
0.015 \\
0.157 \\
0.054 \\
0.815 \\
-0.007 \\
-0.03 E \\
0.015 \\
-0.05 E \\
-0.135\end{array}$ \\
\hline
\end{tabular}

\begin{tabular}{lr}
\multicolumn{2}{c}{ Kegression Dutput: } \\
Constant & 0.147 \\
Std Err of Y Est & 1.034238 \\
Fi Squared & 0.999727 \\
No. of Gbservations & 11 \\
Degrees of Freedom & 9
\end{tabular}

$\begin{array}{ll}X \text { Coefficient(s) } & 0.951545 \\ \text { Std Err of Coef. } & 0.049305\end{array}$

DISCLAIMER

This report was prepared as an account of work sponsored by an agency of the United States Government. Neither the United Stales Government nor any agency thereof, nor any of their employees, makes any warranty, express or implied, or assumes any legal liability or responsibility for the accuracy, completeness, or usefulness of any information, apparutus, product, or process disclosed, or represents that its use would not infringe privately owned rights. Refercoce herein to any specific commercial produch, process, or service by trade name, trademark, manufacturer, or otherwise daes not necessarily constitute or imply its endorsement, recommendation, or favoring by the United States Government or any agency thereof. The views and opinions of authors moressed herein do not necessarily state or reflect those of the United States Government or any agency thereof. 